\title{
Complexing of $\mathrm{Al}+3$ by S-2 lons in Alkali Halide Melts
}

\section{Berg, Rolf W.; Bjerrum, Niels}

Published in:

Journal of The Electrochemical Society

Link to article, DOI:

$10.1149 / 1.2119973$

Publication date:

1983

\section{Document Version}

Publisher's PDF, also known as Version of record

Link back to DTU Orbit

Citation (APA):

Berg, R. W., \& Bjerrum, N. (1983). Complexing of Al+3 by S-2 lons in Alkali Halide Melts. Journal of The Electrochemical Society, 130(6), 1442-1443. https://doi.org/10.1149/1.2119973

\section{General rights}

Copyright and moral rights for the publications made accessible in the public portal are retained by the authors and/or other copyright owners and it is a condition of accessing publications that users recognise and abide by the legal requirements associated with these rights.

- Users may download and print one copy of any publication from the public portal for the purpose of private study or research.

- You may not further distribute the material or use it for any profit-making activity or commercial gain

- You may freely distribute the URL identifying the publication in the public portal

If you believe that this document breaches copyright please contact us providing details, and we will remove access to the work immediately and investigate your claim. 
nonstoichiometry will improve the electrocatalytic behavior of $\mathrm{RuO}_{2}$ films. Unlike normal semiconductor films, those of $\mathrm{RuO}_{2}$ are generally highly conducting; the main resistance component is probably due to intergranular contact resistance in these microcrystalline layers.

S. Ardizzone, ${ }^{15}$ A. Carugati, ${ }^{15}$ G. Lodi, ${ }^{15}$ and S. Trasatti: ${ }^{15}$ The main point of Dr. Burke's remarks, as we understand it, is that there are no reasons to expect that the electrocatalytic activity of $\mathrm{RuO}_{2}$ electrodes should be influenced by nonstoichiometry since the active surface sites at high anodic potentials are invariably $\mathrm{Ru}(\mathrm{VI})$ species. While we do not feel like agreeing on this concept in principle, we contend that Dr. Burke's criticism is not properly addressed. Figure 1 on p. 1690 and the related comment in our paper clearly point out that "cracked" and "compact" electrodes differ in the surface morphology rather than in the nonstoichiometry. Figure 3 shows that no appreciable difference is observed within each group of electrodes although the nonstoichiometry varies largely, yet a difference possibly exists between the two groups, which may, thus, be related to the surface morphology. Therefore, the message from this paper is that morphology rather than nonstoichiometry is the crucial factor in electrocatalysis at $\mathrm{RuO}_{2}$ anodes.

That the surface morphology can affect the electrocatalytic properties of $\mathrm{RuO}_{2}$ has been shown in our previous work ${ }^{16}$ on $\mathrm{O}_{2}$ evolution on some sets of electrodes. The effect in that case is admittedly more striking, and our conclusions have been confirmed in different laboratories. ${ }^{17}{ }^{18} \mathrm{It}$ has been neatly found ${ }^{18}$ that the degree of crystallinity has a definite effect on the $\mathrm{O}_{2}$ evolution mechanism. The point of zero charge of $\mathrm{RuO}_{2}$ samples has been found ${ }^{19,20}$ to depend on the temperature of preparation and to be related, as expected from theories, with the crystal parameters of the oxide. ${ }^{21}$ All of these observations emphasize the extreme sensitivity of the nature of the active sites to the morphology of the surface.

Dr. Burke contends that the degree of hydration is not expected to be important in imparting the electrocatalytic properties. It is well established, however, that a number of properties of $\mathrm{RuO}_{2}$ are closely interrelated as a function of the temperature of preparation. ${ }^{16,22}$ Thus, the residual hydration decreases as $T$ increases and at the same time the crystallinity increases. Hydration is presumably located in grain boundaries or at "inner" surfaces (pores, etc.). As the crystallites of $\mathrm{RuO}_{2}$ grow, defect-rich regions will shrink. That is what Fig. 9 in our paper is devised to point out.

In Dr. Burke's opinion, we have not paid much attention to the above aspect apparently because we have not appreciated some points he touches upon in his comments. (i) Reversibility of the $\mathrm{Cl}_{2}$ reaction: This is easily proved by the fact that we were able to measure the exchange current from equilibrium i-E curves [cf. footnote ${ }^{23}$ ]. The effect of mass transfer on the Tafel slope has been discussed by one of us in a previous paper ${ }^{24}$ precisely in connection with the $\mathrm{Cl}_{2}$ evolution reaction. We think that Losev's results ${ }^{25}$ highlight this aspect at the best. We have also suggested that Losev's idea could account for the results in Fig. 3 but that we cannot offer any definite proof for this. In a chapter written by two of $\mathrm{us}_{1}{ }^{26}$ the contrast between $\mathrm{O}_{2}$ evolution as

${ }^{15}$ Department of Physical Chemistry and Electrochemistry, University of Milan, Milan, Italy.

${ }_{16}$ G. Lodi, E. Sivieri, A. De Battisti, and S. Trasatti, J. Appl. Electrochem., 8135 (1978)

${ }^{17}$ L. I. Krishtalik, Personal communication.

${ }^{1} \mathrm{R}$. Kötz and S. Stucki, Personal communication

19 S. Ardizzone, P. Siviglia, and S. Trasatti, J. Electroanal. Chem. 122, 395 (1981).

${ }_{20}$ A. Daghetti, G. Lodi, and S. Trasatti, Mat. Chem. Phys., 8, 1 (1983).

${ }_{21}$ P. Siviglia, A. Daghetti, and S. Trasatti, Coll. Surf., In press.

$22 \mathrm{~S}$. Trasatti and G. Lodi in "Electrodes of Conductive Metallic Oxides. Part A," S. Trasatti, Editor, p. 301, Elsevier, Amsterdam (1981).

${ }_{23}$ B. V. Tilak, This Journal, 126, 343 (1979).

${ }^{24} \mathrm{~S}$. Trasatti, $i$ bid., 120, 1703 (1973)

25 V. V. Losev, Elektrokhimiya, 17, 733 (1981)

${ }^{26} \mathrm{~S}$. Trasatti and G. Lodi, in "Electrodes of Conductive Metallic Oxides. Part B," S. Trasatti, Editor, p. 521, Elsevier, Amsterdam (1981). a "demanding," irreversible reaction and $\mathrm{Cl}_{2}$ evolution as a reversible, possibly "facile" process has been exhaustively discussed. (ii) Relevance of surface redox behavior: We first suggested ${ }^{27,}{ }^{28}$ that the behavior of $\mathrm{RuO}_{2}$ electrodes should be accounted for in terms of surface redox couples. The involvement of surface redox couples in electrocatalytic reactions has been recently rationalized by Krishtalik. ${ }^{29}$ In any case, it is hard to think that the surface redox behavior is substantially unaffected by the solid phase composition. While the growth of a surface layer of more oxidized species might offset some of the expected differences, the features of the overlayer are still expected to depend on the characteristics of the underlying layers. Prolonged oxygen evolution may lead to a composition profile in the overlayer ${ }^{30}$ which might smooth down initial differences between differently treated samples. However, in the case of $\mathrm{Cl}_{2}$ evolution, the large specific adsorption of $\mathrm{Cl}^{-}$ ions ${ }^{31}$ is to be taken into account when envisaging surface oxidation mechanisms. It is possible that some of the experiments cited by Burke are not sensitive enough to give evidence to surface effects. The free energy of a crystal is certainly affected by nonstoichiometry, and this is expected to be the case also for the surface where additional factors (morphology) have however to be taken into consideration. (iii) Nonstoichiometry and conductivity: Dr. Burke contends that, unlike semiconducting oxides, $\mathrm{RuO}_{2}$ conduction properties are not affected by nonstoichiometry since it is a metallic conductor. Therefore, no improvement in the electrocatalytic properties are to be expected from this point of view. We certainly did not expect any effect of this sort since we drew attention to the metallic features of $\mathrm{RuO}_{2}$ early in our work. ${ }^{27}$ Dr. Burke's statement (with no reference) that the main resistance component in $\mathrm{RuO}_{2}$ films is probably due to intergranular contact resistance has been experimentally substantiated in this laboratory and shown in a paper ${ }^{33}$ where the main goal has been again to emphasize the role of morphology in imparting "apparent semiconducting properties" to $\mathrm{RuO}_{2}$ films or pressed powders.

\section{Complexing of $\mathrm{Al}^{+3}$ by $\mathrm{S}^{-2}$ lons in Alkali Halide Melts}

\section{Z. Nagy, J. L. Settle, J. Padova, and M. Blander} (pp. 2034-2037, Vol. 129, No. 9)

R. W. Berg ${ }^{34}$ and N. J. Bjerrum: ${ }^{34}$ The experiments reported in the technical note by Nagy et al. are very interesting and complement our earlier result $\mathrm{s}^{35}$ in LiCl-CsCl melts. We would like to raise some general criticism regarding the interpretation of these new results in the light of our work, especially in relation to the proposed (and questionable) socalled "charge compensated coulomb complex" or " $4 \mathrm{C}$ " model.

First, consider the question of the degree of complexation between $\mathrm{Al}^{+3}$ and $\mathrm{Cl}^{-}$in sulfide-free chloride melts, either be it $\mathrm{LiCl}-\mathrm{KCl}$ or LiCl-CsCl. Apparently, the authors of the note in their " $4 \mathrm{C}$ " model treat the $\mathrm{Al}^{+3}$ and $\mathrm{Cl}^{-}$as essentially uncomplexed. This is not in agreement with present commonly accepted knowledge, according to which $\left[\mathrm{AlCl}_{4}\right]^{-}$complex ions should be formed under such conditions.

We are sure that this formation of $\left[\mathrm{AlCl}_{4}\right]^{-}$takes place, because the Raman spectra of $\mathrm{AlCl}_{3}$ dissolved in pure chloride melts show a strong polarized band at ca. $347 \mathrm{~cm}^{-1}$. This

${ }^{27}$ S. Trasatti and G. Buzzanca, J. Electroanal. Chem., 29, 1 (1971). ${ }_{29}$ D. Galizzioli, F. Tantardini, and S. Trasatti, J. Appl. Electrochem. 4, 57 (1974)

${ }^{29}$ L. I. Krishtalik, Electrochim. Acta, 26, 329 (1981)

T. Arikado, C. Iwakura, and H. Tamura, Electrochim. Acta, 22, 513 (1977)

${ }_{31}$ R. G. Érenburg, L. I. Krishtalik, and I. P. Yarosherskaya, Elektrokhimiya, 11, 1072 (1975).

${ }_{32}$ T. Arikado, C. Iwakura, and H. Tamura, Electrochim. Acta, 23, 9 (1978).

${ }_{33}$ G Lodi, C. De Asmundis, S. Ardizzone, E. Sivieri, and S. Trasatti, Surf. Technol., 14, 335 (1981).

${ }^{34}$ Chemistry Department A, The Technical University of Denmark, DK-2800 Lyngby, Denmark.

${ }^{35}$ R. W. Berg, S. von Winbush, and N. J. Bjerrum, Inorg. Chem., 19 $2688(1980)$ 
band has been repeatedly interpreted ${ }^{35-38}$ as the characteristic strong $\nu_{1}$ fundamental mode of vibration of the $\left[\mathrm{AlCl}_{4}\right]^{-}$ tetrahedron. The solids $\mathrm{M}\left[\mathrm{AlCl}_{4}\right]$ with $\mathrm{M}=\mathrm{Li}, \mathrm{Na}, \mathrm{K}$, etc. definitely contain tetrahedral $\left[\mathrm{AlCl}_{4}\right]^{-}$ions (according to several definitive single crystal x-ray structure solutions, ${ }^{39}$ and they also give the same $\nu_{1}$ Raman band. ${ }^{39}$ In this way, there can be no doubt that $\mathrm{Al}^{+3}$ predominantly exists as $\left[\mathrm{AlCl}_{4}\right]^{-}$ions in LiCl-KCl melts. This point has been neglected by the authors of the note; they merely mention as a possibility that the bonding between $\mathrm{Al}^{+3}$ and $\mathrm{Cl}^{-}$could be not totally ionic.

Secondly, regarding mixed solutions of $\mathrm{AlCl}_{3}$ and $\mathrm{Li}_{2} \mathrm{~S}$ in pure chloride melts such as $\mathrm{LiCl}-\mathrm{KCl}$ or $\mathrm{LiCl}-\mathrm{CsCl}$ eutectics, the situation is the same though not as clear-cut. Our Raman spectroscopic and other evidence ${ }^{35}$ indicates the formation of polymeric species such as $\left[\mathrm{Al}_{\mathrm{n}} \mathrm{S}_{\mathrm{n}-1} \mathrm{Cl}_{2 \mathrm{n}+2}\right]^{\mathrm{n}-}$ with $n \geq 3$. We are sure, as are the authors of the note, that new complex species are indeed formed upon the addition of sulfides to the solutions of $\mathrm{AlCl}_{3}$ in chloride melts; new Raman bands appear due to these new species (most notably near $325 \mathrm{~cm}^{-1}$ ). ${ }^{35}$ But, contrary to the authors of the note, we find no reason to postulate species devoid of chlorine, such as $\left[\mathrm{Al}_{\mathrm{m}} \mathrm{S}_{n}\right]^{+(3 \mathrm{~m}-2 \mathrm{n})}$. Rather, we have presented evidence that the mixed solution contains $\left[\mathrm{Al}_{\mathrm{n}} \mathrm{S}_{\mathrm{n}} \mathrm{Cl}_{2 \mathrm{n}+2}\right]^{\mathrm{n}-}$ (e.g. the preparation of the pure polymeric compound $\mathrm{CsAlSCl}_{2}$ with a similar Raman spectrum). ${ }^{35}$

The so-called " 4 C" model, like other similar purely electrostatic models in physical chemistry, is simple and easy to use in calculations, but the results are of little or no value as long as chemical bonds are involved. The Raman evidence shows that this is the case in the considered system, and therefore the predictions obtained by the " $4 \mathrm{C}$ " model are of little if any use. This conclusion takes nothing from the value of the experimental results obtained by the authors.

Z. Nagy, ${ }^{40}$ J. L. Settle, ${ }^{40}$ J. Padova, ${ }^{40}$ and M. Blander: ${ }^{40}$ The comments by Berg and Bjerrum are based on a misunderstanding of our use of the concept of complexing which may not have been clearly stated in our paper. We will attempt to clarify our view of this concept in this reply.

In binary systems of any two chlorides, the nearest neighbors of all cations are almost exclusively chloride ions, and all cations are, in a sense, complexed by anions. Thus, the difference between the "complexing" of $\mathrm{Li}^{+}, \mathrm{Al}^{3+}$, or even $\mathrm{K}^{+}$by chloride ions in a solution of $\mathrm{LiCl}, \mathrm{KCl}$, and $\mathrm{AlCl}_{3}$ is one of degree not of kind. It is, of course, proper to define special complexes such as $\mathrm{AlCl}_{4}^{-}$in alkali halide melts where there is strong spectroscopic evidence for the existence of this species and where we believe the $\mathrm{AlCl}_{4}^{-}$is likely to be the major, if not exclusive, $\mathrm{Al}^{3+}$ containing species. Whether other species coexist depends on unknown factors related to the relative sensitivity of detecting these other species. Because there is always some uncertainty about the distribution of species (e.g., there could be some $\mathrm{Al}^{3+}$ ions with coordination other than 4), it is more exact and safer to avoid defining the species in work such as is described in our paper. (This is even more important in other systems where the coordination species are more poorly understood or defined than in melts dilute in $\mathrm{Al}^{3+}$.)

Contrary to Berg and Bjerrum's comment, we did not assume that $\mathrm{Al}^{3+}$ and $\mathrm{Cl}^{-}$are not part of a complex nor that the $\mathrm{AlCl}_{4}^{-}$species does not exist. Thus, their second paragraph results from a misunderstanding of our paper and is not a point of contention. For the purposes of our paper, the definition of such species $\left(\mathrm{AlCl}_{4}^{-}\right)$was irrelevant and unnecessary. The $\mathrm{Al}^{3+}$ ions have some average nearest neighbor environment and could be exclusively four coordinated or could have some distribution of coordination numbers. The $\mathrm{S}^{2-}$ ion will also have some average environment which

${ }^{36}$ G. Torsi, G. Mamantov, and G. M. Begun, Inorg. Nucl. Chem. Lett., 6, $553(1970)$.

${ }^{37}$ H. A. Oye, E. Rytter, P. Klaeboe, and S. J. Cyvin, Acta Chem. Scand., 25, 559 (1971).

${ }^{38} \mathrm{E}$. Rytter H. A Oye S. J Cyvin, B. N. Cyvin, and P. Klaeboe, J. Inorg. Nucl. Chem., 35, 1185 (1973)

${ }_{39}$ See e.g. F. Wallart, A. Lorriaux-Rubbens, G. Mairesse, P. Barbier, and J. P. Wignacourt, J. Raman Spectrose., 9, 55 (1980) and references therein.

${ }^{40}$ Argonne National Laboratory Chemical Technology Division, Argonne, Hlinois 60439. need not be specified. When the $\mathrm{Al}^{+3}$ and $\mathrm{S}^{2-}$ ions associate one can break down the process into two changes. The first is the replacement of a $\mathrm{Cl}^{-}$in the first shell of an $\mathrm{Al}^{3+}$ by $\mathrm{S}^{2-}$ and the replacement of an alkali ion in the first shell of the $\mathrm{S}^{2-}$ by an $\mathrm{Al}^{3+}$ leading to a net energy change of about $-2 e^{2} / d$. The second change is the rearrangement of the other neighboring alkali and halide ions which is related to the compensation or shielding of this interaction. Berg and Bjerrum make the unsupported claim that bonding of the $\mathrm{AlS}^{+}$and $\mathrm{AlCl}_{4}^{-}$species is "chemical" in nature. The word chemical is undefined in this context. In addition, there are no analyses of the energetics of these species to support any bonding type. Indeed, however unlikely it is, one can have $\mathrm{AlCl}_{4}^{-}$species in solution even if the bonds were purely ionic. If "chemical" is defined as non-coulombic interactions then, of course, noncoulomb forces are undoubtedly significant but they are likely to be smaller than the large coulomb forces involved (unless sulfide ions in solution have charges close to -1 ). To be important, the noncoulomb energy of interaction of $\mathrm{Al}^{3+}$ with a nearest neighbor chloride ion must be more negative than the noncoulomb energy of interaction of $\mathrm{Al}^{+3}$ with a nearest neighbor sulfide ion by an amount close in magnitude to the cou lomb energy. This seems unlikely but, of course, is not impossible. Quantum mechanical calculations of the energetics of these species are underway. ${ }^{41}$

The average coulomb complex has an unknown and generally unspecified number of alkali and chloride ions of the solvent as near neighbors. To do as Berg and Bjerrum have done and single out a small number of solvating chlorides to be part of the complex is speculative and may not represent the real species, which could readily have a broad distribution of different ionic environments which could be extremely difficult, if not impossible to observe by any known structural measurement. From a thermodynamic point of view, the solvent ions in the environment are irrelevant if both $\mathrm{Al}^{3+}$ and $\mathrm{S}^{2-}$ are at low concentrations.

Berg and Bjerrum do bring out an important point concerning larger complexes. Although we felt that the evidence favored the simple $\mathrm{AlS}^{+}$complex (albeit solvated by solvent cations and anions), we could not rule out the importance of larger species as we stated in our paper.

It is unfortunate that Berg and Bjerrum contribute to the confusion concerning the differences between complexing in additive binary systems (e.g., $\left.\mathrm{K}^{+}, \mathrm{Al}^{3+} / \mathrm{Cl}^{-}\right)$and in reciprocal systems (e.g., $\left.\mathrm{K}^{+}, \mathrm{Al}^{3+} / \mathrm{Cl}^{-}, \mathrm{S}^{2-}\right)$. In the first case, all cations are "complexed" and one considers as "true" complexes those special and presumably tightly bound species where structural data are available to define the structure of all the binary chloride systems, those containing $\mathrm{Al}^{3+}$ ions are probably the clearest examples of systems with "true" complexes. For a major fraction of binary chloride systems, there is some uncertainty and there are many shades of gray. Even for the "true" complexes, the structural information by itself says nothing about the energetics and type of bonding which might even be largely ionic. Thus, evidence for the existence of a complex is of no value in understanding the energetics of reaction of $\mathrm{Al}^{3+}$ ions with sulfide or oxide ions. In reciprocal systems at low concentrations of solute cations and anions, a complex is formed between the solute ions when they are each others nearest neighbors with a greater than random probability. The configurations of the solvent ions about the separated solute ions and about the complex are usually not considered in defining such complexes. This type of complex is less subject to uncertainty in definition than the type in additive systems. Our point is that the coulomb attractions between $\mathrm{S}^{2-}$ (or any other polyvalent anion) with polyvalent cations in alkali halides (a reciprocal system) are very large and are likely to dominate the energetics of complex formation. Our 4C model provides a basis for predicting species which are likely to complex strongly. The accuracy of the model can be tested and improved in a well-defined manner with the use of molecular dynamics and quantum mechanical calculations under development for calculating the influence of shielding and of noncoulomb forces: If non-coulomb (e.g., covalent) forces are important they could even enhance the effects we discussed. By contrast, Berg and Bjerrum do not offer any testable alternative.

${ }^{41}$ L. A. Curtiss, Personal communication. 